\title{
SCHMITZ, Gerhard, De presbiteris criminosis. Ein Memorandum Erzbischof Hinkmars von Reims über straffällige Kleriker
}

\section{Philippe Depreux}

\section{(2) OpenEdition}

\section{Journals}

Édition électronique

URL : http://journals.openedition.org/ifha/821

DOI : $10.4000 /$ ifha. 821

ISSN : 2198-8943

\section{Éditeur}

IFRA - Institut franco-allemand (sciences historiques et sociales)

Référence électronique

Philippe Depreux, «SCHMITZ, Gerhard, De presbiteris criminosis. Ein Memorandum Erzbischof Hinkmars von Reims über straffällige Kleriker », Revue de l'IFHA [En ligne], Date de recension, mis en ligne le 01 janvier 2005, consulté le 22 septembre 2020. URL : http://journals.openedition.org/ifha/821 ; DOI : https://doi.org/10.4000/ifha.821

Ce document a été généré automatiquement le 22 septembre 2020.

(CIFHA 


\title{
SCHMITZ, Gerhard, De presbiteris criminosis. Ein Memorandum Erzbischof Hinkmars von Reims über straffällige Kleriker
}

\author{
Philippe Depreux
}

C'est dans le cadre des travaux préparatoires à son édition de la collection canonique de Benoît le Lévite, dont deux chapitres ouvrent le traité d'Hincmar de Reims sur les prêtres délinquants, que G.S. s'est intéressé à ce texte de nature bâtarde. La structure de l'argumentation autorise l'hypothèse selon laquelle il s'agirait d'une lettre adressée au pape, pour défendre les prérogatives de l'évêque diocésain dans les affaires délictueuses (des affaires de mœurs pour l'essentiel) impliquant des prêtres, apparemment souvent tentés d'aller plaider leur cause à Rome et d'en revenir blanchis sans qu'une véritable enquête ait pu avoir lieu. Toutefois, ce texte ne respecte pas les formes épistolaires. Il se peut donc qu'on ait plutôt affaire à un mémorandum présentant ainsi un intérêt tout particulier pour l'historien : à mi-chemin entre un dossier de travail rassemblant de manière informe des extraits canoniques ou des autorités patristiques et un traité composé en fonction d'un destinataire particulier, cette collection jette un éclairage nouveau sur les méthodes de travail de l'archevêque de Reims (qui n'apparait pas nommément comme l'auteur dans le manuscrit berlinois de référence, copié à Reims vers la fin du IXe s., mais dont le style trahit l'identité). La tendance qu'a Hincmar à se citer soi-même d'un traité ou d'une lettre à l'autre et à reprendre la même matière (en la formulant de mémoire ou après avoir consulté quelque codex de référence) rend particulièrement difficile - voire impossible - la distinction entre ce qui est original et ce qui relève de la réception d'un texte précis. L'édition critique de ce traité, qui tire son nom du chapitre de la collection de Benoît le Lévite cité en exergue (mais le manuscrit de référence porte le titre : De accusatoribus ac testibus in presbiteros et quomodo se defendant, qui reflète mieux la teneur du texte), était d'autant plus souhaitable que les versions dont on disposait jusqu'alors l'editio princeps de J. Busaeus (1602) et sa reprise par J. Sirmond (1645), puis J.-P. Migne 
dans sa Patrologie latine - s'avèrent particulièrement fautives. L'intérêt de la présente publication n'est pas seulement fondé sur la qualité de l'édition critique, mais aussi sur la mise en perspective historique que G.S. propose en introduction, brossant un tableau en négatif de la société carolingienne et des conditions de vie du bas clergé, dont certains hasards documentaires permettent de se faire une idée (à cet égard, on peut regretter que l'ouvrage, qui compte une liste des sources et un index rerum détaillé, ne répertorie pas les noms propres cités en introduction). Par ailleurs, à la p. 30, G.S. attire l'attention sur des formules de serment tombées dans l'oubli, faute notamment d'avoir été intégrées par K. Zeumer dans son édition des Formulae : ces formules, éditées au XVIe s. par M. Freher, complètent le propos d'Hincmar sur les procédures judiciaires en livrant la teneur que pouvaient revêtir les serments purgatoires (deux exemples, dont l'un faisant explicitement mention de l'évêque de Reims, Hincmar) et les serments prêtés par les co-jureurs (l'exemple cité révèle de manière exceptionnellement claire la nature de tels serments prêtés par les garants de la bonne foi de la personne souhaitant ainsi se disculper : ils affirment, en se référant à Dieu et à ses saints, qu'ils croient à la véracité des dires de la personne en cause). A cet égard, l'édition du traité De presbiteris criminosis ne retient pas seulement l'attention du spécialiste d'histoire ecclésiastique et du canoniste, mais aussi de tout historien s'intéressant aux pratiques judiciaires. 